\title{
MUTU PELAYANAN KESEHATAN MENINGKAT DENGAN MENERAPKAN KESELAMATAN PASIEN DI PUSKESMAS
}

\author{
Linardita Ferial $^{1}$, Nova Wahyuni ${ }^{1}$ \\ ${ }^{1}$ Universitas Banten Jaya, Jl. Syekh Nawawi Al-bantani, Kota Serang, Banten \\ E-Mail:linarditaferial@unbaja.ac.id
}

\begin{abstract}
Patient safety is an indicator of health service quality that becomes an important issue although data of patient safety incident at primary health care are not always accurate in Indonesia. Public health center is a health service facility that implements patient safety to improve the health service quality as stated in Health Ministry Law Republic of Indonesia Number 36 Year 2009. The aim of this study was to identify the implementation of patient safety to improve the service quality. Data collection techniques used were observation, interview, and literature study. The research was done at a public health center in Serang City from April to May 2021. The results showed that the implementation of patient safety at the public health center was adjusted to the accreditation standard of the public health center. However, there are still some obstacles and shortcomings in the fulfillment of patient safety standards, so it is necessary to optimize the implementation of patient safety from all stakeholders. It can be concluded that public health centers should provide safe and qualified services to achieve healthy disctrict. The public health centers also need to improve the patient safety according to Health Ministry Law Republic of Indonesia Number 36 Year 2009.
\end{abstract}

Keywords: health service quality, patient safety, public health center

\begin{abstract}
ABSTRAK
Keselamatan pasien merupakan salah satu indikator kualitas pelayanan kesehatan. Meskipun data insiden keselamatan pasien di fasilitas pelayanan kesehatan tingkat pertama belum akurat di Indonesia, namun keselamatan pasien menjadi isu penting dalam peningkatan kualitas pelayanan. Puskesmas "X" Kota Serang adalah salah satu fasilitas pelayanan kesehatan yang menerapkan upaya keselamatan pasien sebagai salah satu bentuk upaya peningkatan mutu pelayanan kesehatan sebagaimana dimaksud dalam Undang-Undang Republik Indonesia Nomor 36 Tahun 2009. Tujuan penelitian ini yaitu mengidentifikasi penerapan upaya keselamatan pasien di Puskesmas " $X$ " Kota Serang untuk meningkatkan kualitas pelayanan. Teknik pengumpulan data yang digunakan adalah observasi, wawancara, dan studi literatur. Pengambilan data dilakukan di Puskesmas " $\mathrm{X}$ " Kota Serang pada bulan April-Mei 2021. Hasil analisis data menunjukkan bahwa pelaksanaan upaya keselamatan pasien Puskesmas "X" Kota Serang disesuaikan dengan standar penilaian akreditasi Puskesmas. Namun, dalam realisasinya masih terdapat hambatan dan kekurangan dalam pemenuhan standar upaya keselamatan pasien di Puskesmas " $X$ " Kota Serang sehingga perlu optimalisasi penerapan upaya keselamatan pasien dari seluruh pihak yang terlibat sehingga puskesmas harus menyediakan pelayanan yang aman dan bermutu untuk mewujudkan kecamatan sehat. Puskesmas perlu untuk meningkatkan keselamatan pasien sesuai dengan Permenkes Republik Indonesia Nomor 36 Tahun 2009.
\end{abstract}

Kata Kunci: Keselamatan Pasien, Mutu Pelayanan Kesehatan, Puskesmas 


\section{INTRODUCTION}

Pembangunan kesehatan sebagai bagian dari pembangunan nasional mempunyai tujuan untuk meningkatkan kemauan dan kemampuan serta kesadaran hidup sehat bagi setiap orang supaya terwujud derajat kesehatan masyarakat yang optimal. Undang - undang Republik Indonesia Nomor 36 Tahun 2009 tentang kesehatan pasal 5 menyebutkan bahwa setiap orang mempunyai hak dalam memperoleh pelayanan kesehatan yang aman, bermutu dan terjangkau.

Puskesmas merupakan salah satu fasilitas pelayanan kesehatan yang bertanggung jawab menyelenggarakan upaya kesehatan, baik promotif, preventif, kuratif, maupun rehabilitatif di suatu wilayah kerja. Puskesmas sebagai penyelenggara pembangunan kesehatan merupakan bagian integral dari pembangunan nasional. Tujuan diselenggarakannya pembangunan kesehatan adalah meningkatkan kesadaran, kemauan dan kemampuan hidup sehat bagi setiap orang supaya terwujud derajat kesehatan masyarakat yang optimal, baik secara sosial maupun ekonomi.

Puskesmas " $X$ " Kota Serang merupakan salah satu fasilitas pelayanan kesehatan tingkat pertama yang menjalankan fungsinya sebagai penyelenggara Upaya Kesehatan Perorangan (UKP) dan Upaya Kesehatan Masyarakat (UKM) serta bertujuan untuk meningkatkan derajat kesehatan di wilayah kerjanya. Berdasarkan Permenkes No. 46 Tahun 2015 tentang Akreditasi Puskesmas, Klinik Pratama, Tempat Praktik Mandiri Dokter, dan Tempat Praktik Mandiri Dokter Gigi pada bagian lampiran I Standar Akreditasi Puskesmas menyebutkan bahwa puskesmas dapat menjalankan fungsinya secara optimal perlu dikelola dengan baik mulai dari sumber daya yang digunakan, proses pelayanan hingga kinerja pelayanan sebab masyarakat menghendaki pelayanan kesehatan yang aman dan bermutu, serta dapat menjawab kebutuhan mereka. Oleh karena itu upaya peningkatan mutu, manajemen risiko dan keselamatan pasien perlu diterapkan dalam pengelolaan Puskesmas dalam memberikan pelayanan kesehatan yang komprehensif kepada masyarakat melalui upaya pemberdayaan masyarakat dan swasta (Permenkes, 2015).

Keselamatan pasien menurut Permenkes RI No. 11 Tahun 2017 tentang Keselamatan Pasien adalah sistem yang membuat asuhan pasien lebih aman, meliputi asesmen risiko, identifikasi dan pengelolaan risiko pasien, pelaporan dan analisis insiden, kemampuan belajar dari insiden dan tindak lanjutnya, serta implementasi solusi untuk meminimalkan timbulnya risiko dan mencegah terjadinya cedera yang disebabkan oleh kesalahan akibat melaksanakan suatu tindakan atau tidak mengambil tindakan yang seharusnya diambil.

Upaya Keselamatan Pasien yang diterapkan oleh Puskesmas X Kota Serang bertujuan untuk meningkatkan mutu pelayanan fasilitas pelayanan kesehatan melalui penerapan manajemen risiko yang diterapkan ke seluruh aspek pelayanan yang disediakan oleh Puskesmas X Kota Serang. Selain itu, upaya keselamatan pasien juga menjamin bahwa seluruh tindakan dalam pelayanan kesehatan dilaksanakan sesuai dengan standar pelayanan minimal dan kode etik profesi tenaga kesehatan.

Tingginya angka insiden keselamatan pasien menjadi dasar pentingnya upaya keselamatan 
pasien di fasilitas pelayanan kesehatan. Dalam rentang waktu Januari-Maret 2021, National Patient Safety Agency melaporkan angka kejadian keselamatan pasien dari negara Inggris sebanyak 1.879.822 kejadian. Kementerian Kesehatan Malaysia (Ministry of Health Malaysia) melaporkan angka insiden keselamatan pasien dalam rentang waktu Januari-Maret 2021 sebanyak 3.258 kejadian dan untuk negara Indonesia dalam rentang waktu 2015 - 2020 KPPRS melaporkan terdapat 877 kejadian keselamatan pasien.

Banyak faktor yang menyebabkan tingginya angka Insiden Keselamatan Pasien (IKP) di fasilitas pelayanan kesehatan. Selain faktor penyebab, dampak yang ditimbulkan dari Insiden Keselamatan Pasien juga beragam salah satunya adalah menurunnya kepuasan pasien sehingga berpengaruh terhadap mutu dari pelayanan kesehatan tersebut. Pelayanan yang aman dapat meningkatkan kepuasan pasien sehingga memberikan pengaruh yang baik terhadap citra dari sebuah fasilitas pelayanan kesehatan.

\section{METHOD}

Artikel ilmiah ini merupakan jenis artikel ilmiah deskriptif. Teknik pengumpulan data yang dilakukan adalah dengan observasi langsung, wawancara dan studi literatur berdasarkan kebijakan dan dokumen yang terkait dengan mutu dan keselamatan pasien. Observasi langsung dilakukan untuk melihat proses pelaksanaan upaya keselamatan pasien di Puskesmas ' $X$ ' Kota Serang. Wawancara dilakukan kepada tim Mutu dan Keselamatan Pasien dengan menggunakan panduan wawancara yang disesuaikan dengan Permenkes No. 46 Tahun 2015 dan Instrumen Akreditasi Puskesmas. Sedangkan dokumen yang digunakan sebagai literatur adalah pedoman, kebijakan dan/atau peraturan yang berlaku terkait mutu dan keselamatan pasien. Pengumpulan data dilaksanakan di Puskesmas ' $\mathrm{X}$ ' Kota Serang pada bulan April-Mei 2021.

\section{RESULTS AND DISCUSSION}

\section{Mutu Pelayanan Kesehatan}

Menurut Edward Deming (1940), Mutu adalah pelayanan yang dapat memuaskan pelanggan, Menurut Joseph M. Juran (1954), bahwa mutu merupakan kecocokan penggunaan produk untuk memenuhi kepuasan pelanggan. Sedangkan menurut Supriyanto \& Wulandari (2011), mutu merupakan keseluruhan karakteristik dan gambaran dari barang atau jasa yang menunjukkan kemampuannya dalam memuaskan kebutuhan pelanggan. Sehingga dapat dikatakan bahwa mutu adalah sesuatu yang digunakan untuk menjamin tujuan atau luaran yang diharapkan dan mutu harus selalu mengikuti perkembangan pengetahuan professional terkini supaya dapat memuaskan pelanggan.

Mutu pelayanan kesehatan adalah derajat atau tingkat kesempurnaan pelayanan kesehatan yang diselenggarakan sesuai dengan standar pelayanan yang berlaku. Menurut Azwar (1996), mutu pelayanan kesehatan bersifat multidimensi sebab mutu pelayanan kesehatan dapat dilihat dari tiga sudut pandang yaitu dari pihak pemakai jasa pelayanan, pihak penyelenggara pelayanan, dan pihak dan pihak 
penyandang dana mutu.

Berdasarkan Permenkes No. 46 Tahun 2015 Lampiran I Standar Akreditasi Puskesmas disebutkan bahwa visi pembangunan kesehatan yang diselenggarakan oleh Puskesmas adalah tercapainya Kecamatan Sehat menuju terwujudnya Indonesia Sehat. Untuk mewujudkan tercapainya Kecamatan Sehat, pelayanan kesehatan khususnya Puskesmas harus memiliki kemampuan memberikan pelayanan kesehatan yang bermutu, aman, serta dapat menjawab kebutuhan masyarakat. Peningkatan mutu merupakan suatu proses pengukuran derajat kesempurnaan pelayanan kesehatan dibandingkan dengan standar atau prinsip dengan tindakan perbaikan yang sistematik dan berkesinambungan untuk mencapai mutu pelayanan yang optimum atau prima sesuai dengan standar ilmu pengetahuan dan teknologi serta kemampuan sumber daya yang ada (Supriyanto \& Wulandari, 2011).

Kualitas atau mutu pelayanan kesehatan tidak dapat lepas dari kepuasan pelanggan atau pasien. Pelayanan kesehatan yang bermutu dapat meningkatkan kepuasan pasien terhadap pelayanan yang diberikan. Selain itu, kepuasan pasien dapat dijadikan tolok ukur keberhasilan mutu pelayanan sebuah fasilitas kesehatan. Kepuasan pasien akan tercipta ketika apa yang didapat lebih besar dari yang diharapkan. Menurut Kotler dalam Cahyono (2008), kepuasan dan keselamatan pasien dengan tatakelola klinis serta efisiensi merupakan hal penting dalam menjamin kualitas pelayanan kesehatan. Institute of Medicine (2001) juga mengatakan hal yang sama, yaitu mutu sebuah pelayanan kesehatan dapat berdasarkan pada efisiensi, efektifitas, ketepatan waktu, keadilan, berorientasi pasien, dan keselamatan pasien. Hal tersebut menunjukkan bahwa keselamatan pasien merupakan salah satu tolak ukur bagi penilaian kualitas sebuah pelayanan kesehatan termasuk Puskesmas.

Berdasarkan studi literatur terkait mutu pelayanan di Puskesmas ' $\mathrm{X}$ ' Kota Serang, disebutkan bahwa terdapat beberapa manajemen yang diterapkan guna meningkatkan mutu pelayanan sesuai kebutuhan dan kemampuan di Puskesmas ' $X$ ' Kota Serang. Salah satu manajemen yang digunakan untuk meningkatkan mutu pelayanan di Puskesmas ' $\mathrm{X}$ ' Kota Serang adalah manajemen risiko. Hal tersebut sesuai dengan Permenkes No. 11 Tahun 2017 tentang Keselamatan Pasien, bahwa keselamatan pasien memiliki tujuan untuk meningkatkan kualitas atau mutu pelayanan kesehatan melalui pelaksanaan manajemen risiko di seluruh aspek pelayanan kesehatan yang tersedia di pelayanan kesehatan tersebut.

\section{Upaya Keselamatan Pasien}

Keselamatan adalah suatu sistem yang membuat asuhan pasien lebih aman, meliputi asasmen risiko, identifikasi dan pengelolaan risiko pasien, pelaporan dan analisis insiden, kemampuan belajar dari insiden dan tindak lanjutnya, serta implementasi solusi untuk meminimalkan timbulnya risiko dan mencegah terjadinya cedera yang disebabkan oleh kesalahan akibat melaksanakan suatu tindakan atau tidak mengambil tindakan yang seharusnya.

Salah satu prinsip pelayanan kesehatan adalah menyelamatkan pasien dengan prosedur dan 
tindakan yang aman dan tidak membahayakan pasien maupun petugas pemberi pelayanan kesehatan. Setiap fasilitas layanan kesehatan harus selalu menjaga keamanan proses pelayanan kesehatannya guna menghindari terjadinya kesalahan medis (medical error) yang bisa berpengaruh terhadap kualitas pelayanan kesehatan.

Keselamatan pasien merupakan suatu upaya menjamin segala tindakan dan aktivitas yang berhubungan dengan pasien yang dilakukan oleh petugas kesehatan supaya berlangsung dengan aman dan tidak menimbulkan efek atau dampak yang membahayakan bagi pasien melalui serangkaian aktivitas yang telah diatur dalam perundang-undangan.

Keselamatan pasien menjadi poin penting dalam setiap tindakan medis baik tindakan medis ringan maupun tindakan medis berat. Berdasarkan penelitian Maghfiroh \& Rochmah (2017), keselamatan pasien memberikan pengaruh besar terhadap citra, tanggung jawab sosial, moral serta kinerja petugas kesehatan sehingga keselamatan pasien memiliki keterkaitan dengan isu mutu dan citra sebuah pelayanan kesehatan termasuk puskesmas.

Berdasarkan Permenkes No. 46 Tahun 2015, bahwa fasilitas kesehatan diharuskan memperhatikan mutu pelayanan dan keselamatan pasien dalam setiap kegiatan pelayanan dan dilakukan secara berkesinambungan. Berdasarkan penelitian Firawati, dkk. (2012), pelaksanaan keselamatan pasien dan budaya keselamatan pasien di sebuah fasilitas pelayanan kesehatan dapat dipengaruhi oleh beberapa faktor yaitu pengorganisasian, lingkungan kerja, dan faktor budaya.

Dalam pelaksanannya, upaya keselamatan pasien memerlukan pemantauan yang berkesinambungan agar pelaksanaannya sesuai dengan tujuan. Berdasarkan penelitian Samra, R., dkk. (2016), bahwa terdapat beberapa strategi monitoring yang dapat digunakan sebagai metode pemantauan dalam implementasi upaya keselamatan pasien. Strategi monitoring yang digunakan dapat disesuaikan dengan kebutuhan, kemampuan dan kondisi fasilitas pelayanan kesehatan.

Monitoring upaya keselamatan pasien bertujuan untuk memastikan bahwa pelaksanaan upaya keselamatan pasien telah sesuai dengan standar dan kriteria yang telah disepakati. Sedangkan strategi monitoring merupakan sebuah metode yang dipilih dan digunakan guna memudahkan dalam proses pemantauan dan penemuan hambatan-hambatan selama pelaksanaan upaya keselamatan pasien. Oleh karena itu, sebagai bentuk strategi monitoring terhadap upaya keselamatan pasien di Puskesmas, Pemerintah Indonesia mengeluarkan sebuah kebijakan yang mengatur terkait standar dan kriteria penilaian pelaksanaan upaya keselamatan pasien dalam Permenkes No. 46 Tahun 2015.

Berdasarkan kebijakan tersebut, disebutkan bahwa untuk menjamin perbaikan mutu, peningkatan kerja dan penerapan manajemen risiko dilaksanakan secara berkesinambungan di Puskesmas, maka perlu dilakukan penilaian oleh pihak eksternal dengan menggunakan standar yang ditetapkan yaitu melalui mekanisme akreditasi. Salah satu elemen penilaian dalam akreditasi adalah peningkatan mutu klinis dan keselamatan pasien yang tercantum dalam instrumen akreditasi Puskesmas BAB IX. 
Puskesmas ' $X$ ' Kota Serang merupakan salah satu Puskesmas di Kota Serang yang telah terakreditasi. Berdasarkan hasil wawancara dan observasi lapangan, pelaksanaan upaya keselamatan pasien di Puskesmas X disesuaikan dengan point elemen penilaian instrument akreditasi Puskesmas. Berikut merupakan hasil wawancara dan observasi langsung terkait pelaksanaan upaya keselamatan pasien di Puskesmas X berdasarkan Instrumen Akreditasi Puskesmas BAB IX. Berdasarkan Tabel 1, terdapat 2 standar upaya keselamatan pasien dalam instrumen akreditasi Puskesmas BAB IX tentang peningkatan mutu klinis dan keselamatan pasien yang belum terlaksana dengan baik di Puskesmas X Kota Surabaya, yaitu (1) Upaya keselamatan pasien dipahami dan didefinisikan dengan baik oleh semua pihak yang berkepentingan dan (2) Pengukuran, pengumpulan dan evaluasi sasaran keselamatan pasien.

Tabel 1. Pelaksanaan Keselamatan Pasien di Puskesmas ' $X$ ' Kota Serang

\begin{tabular}{|c|c|c|c|}
\hline No & Standar & Kondisi di Lapangan & Telaah \\
\hline 1 & $\begin{array}{l}\text { Perencanaan, monitoring, } \\
\text { dan evaluasi upaya } \\
\text { keselamatan pasien } \\
\text { menjadi tanggung jawab } \\
\text { tenaga yang bekerja di } \\
\text { pelayanan klinis }\end{array}$ & $\begin{array}{l}\text { Puskesmas X Kota Serang telah } \\
\text { memiliki dokumen lengkap } \\
\text { terkait dengan perencanaan, } \\
\text { monitoring, dan evaluasi upaya } \\
\text { keselamatan pasien serta Surat } \\
\text { Keputusan (SK) tentang } \\
\text { penetapan tim Mutu dan } \\
\text { Keselamatan Pasien beserta } \\
\text { uraian tugasnya. }\end{array}$ & $\begin{array}{l}\text { Telah sesuai dengan } \\
\text { standar }\end{array}$ \\
\hline 2 & $\begin{array}{l}\text { Upaya Keselamatan Pasien } \\
\text { dipahami dan didefinisikan } \\
\text { dengan baik oleh semua } \\
\text { pihak yang berkepentingan }\end{array}$ & $\begin{array}{l}\text { Terdapat beberapa petugas } \\
\text { Puskesmas X Kota Serang yang } \\
\text { masih belum memahami dengan } \\
\text { baik alur pelaporan Insiden } \\
\text { Keselamatan Pasien (IKP) dan } \\
\text { terdapat petugas yang tidak } \\
\text { konsisten dalam melakukan } \\
\text { pencatatan dan pelaporan } \\
\text { keselamatan pasien. }\end{array}$ & $\begin{array}{l}\text { Masih kurangnya sosialisasi } \\
\text { kepada seluruh petugas yang } \\
\text { terlibat terkait dengan upaya } \\
\text { keselamatan pasien di } \\
\text { Puskesmas X Kota Serang }\end{array}$ \\
\hline 3 & $\begin{array}{l}\text { Pengukuran, pengumpulan } \\
\text { dan evaluasi sasaran } \\
\text { keselamatan pasien }\end{array}$ & $\begin{array}{l}\text { Pengukuran, pengumpulan dan } \\
\text { evaluasi sasaran keselamatan } \\
\text { pasien di Puskesmas X Kota } \\
\text { Serang dilaksanakan secara rutin } \\
\text { setiap bulan Namun terkadang } \\
\text { pelaksanaannya tidak sesuai } \\
\text { dengan jadwal. }\end{array}$ & $\begin{array}{l}\text { Masih kurangnya komitmen } \\
\text { dalam ketepatan waktu } \\
\text { pengukuran, pengumpulan } \\
\text { dan evaluasi sasaran } \\
\text { keselamatan pasien di } \\
\text { Puskesmas X Kota Serang }\end{array}$ \\
\hline 4 & $\begin{array}{lr}\text { Hasil perbaikan } & \text { upaya } \\
\text { keselamatan } & \text { pasien } \\
\text { dievaluasi } & \text { dan } \\
\text { dikomunikasikan } & \text { dengan } \\
\text { baik } & \end{array}$ & $\begin{array}{l}\text { Tindak lanjut yang diambil } \\
\text { terkait dengan perbaikan upaya } \\
\text { keselamatan pasien di } \\
\text { Puskesmas X Kota Serang } \\
\text { dicatat dan didokumentasikan } \\
\text { serta ditempel pada papan } \\
\text { informasi Puskesmas X Kota } \\
\text { Serang sebagai bahan evaluasi } \\
\text { dan media komunikasi kepada } \\
\text { pasien. Selain itu, hasil evaluasi } \\
\text { perbaikan upaya keselamatan } \\
\text { pasien disosialisasikan kepada }\end{array}$ & Telah sesuai standar \\
\hline
\end{tabular}




\begin{tabular}{llll}
\hline No Standar & \multicolumn{1}{c}{ Kondisi di Lapangan } & Telaah \\
\hline & $\begin{array}{l}\text { seluruh petugas di masing- } \\
\text { masing unit kerja sebagai bahan } \\
\text { pembelanjaran. }\end{array}$ \\
\hline
\end{tabular}

Standar pertama dalam pelaksanaan upaya keselamatan pasien di Puskesmas adalah perencanaan, monitoring, dan evaluasi upaya keselamatan pasien menjadi tanggung jawab tenaga yang bekerja di pelayanan klinis. Berdasarkan observasi dan wawancara dengan beberapa pihak di Puskesmas X Kota Serang, bahwa perencanaan, monitoring, dan evaluasi upaya keselamatan pasien sudah dilakukan sesuai dengan kebijakan dan pedoman yang berlaku.

Berdasarkan observasi langsung, terdapat dokumen perencanaan, hasil monitoring dan evaluasi pelaksanaan upaya keselamatan pasien di Puskesmas X Kota Serang. Hal tersebut menunjukkan bahwa tim keselamatan pasien telah menjalankan tugasnya dalam pelaksanaan upaya keselamatan pasien di Puskesmas X Kota Serang. Pelaksanaan upaya keselamatan pasien tidak dapat dilakukan hanya oleh tim keselamatan pasien atau petugas kesehatan dengan pasien yang bersangkutan dan teknologi yang mendukung, melainkan harus melibatkan seluruh bagian dari organisasi yaitu dalam bentuk dukungan manajemen dan kerjasama antar staf yang baik (Sumarmi, 2017). Robbins dan Judge (2008), menyatakan bahwa kerja sama tim yang baik dibutuhkan dalam menghasilkan sinergi yang positif dalam mencapai suatu tujuan organisasi.

Upaya keselamatan pasien harus dipahami dan didefinisikan dengan baik oleh seluruh pihak yang terlibat agar penerapan upaya keselamatan pasien dapat berjalan dengan baik dan mencapai tujuan yang diinginkan. Salah satu tujuan dari upaya keselamatan pasien yang tercantum dalam dokumen Kerangka Acuan Kerja Puskesmas X Kota Serang adalah untuk meningkatkan mutu pelayanan dan kepuasan pasien. Penerapan upaya keselamatan pasien untuk peningkatan mutu pelayanan kesehatan tidak hanya terkait dengan petugas atau sumber daya manusia yang terlibat. Namun penciptaan lingkungan yang aman dan terhindar dari hal-hal yang berpotensi membahayakan bagi pasien juga merupakan bentuk upaya keselamatan pasien (Ulrich \& Kear, 2014).

Berdasarkan hasil observasi di Puskesmas X Kota Serang, terdapat beberapa petugas yang Puskesmas yang belum memahami dengan baik alur pelaporan Insiden Keselamatan Pasien. Petugas tersebut hanya mencatat namun tidak dilaporkan sesuai batas waktu pelaporan yang ditentukan karena masih bingung dengan alur pelaporan insiden keselamatan pasien. Selain itu, terdapat petugas yang tidak konsisten melakukan pencatatan dan pelaporan keselamatan pasien. Hal tersebut dikarenakan petugas belum sepenuhnya memahami pentingnya pencatatan dan pelaporan dalam upaya keselamatan pasien.Hal tersebut sejalan dengan penelitian yang dilakukan oleh Gunawan, Widodo, \& Harijanto (2015), bahwa rendahnya pemahaman dan pengetahuan petugas terkait tata cara dan manfaat pelaporan IKP dapat menurunkan kinerja petugas dalam melakukan pencatatan dan pelaporan IKP.

Berdasarkan wawancara dengan anggota tim keselamatan pasien, dikatakan bahwa masih 
kurangnya sosialisasi terkait upaya keselamatan pasien kepada petugas Puskesmas sehingga masih terdapat beberapa petugas yang belum memahami dengan baik hal-hal terkait upaya keselamatan pasien di Puskesmas X Kota Serang. Pengukuran, pengumpulan dan evaluasi sasaran keselamatan pasien sebagaimana dimaksud dalam Permenkes No. 46 tahun 2015 tentang Akreditasi Puskesmas, Klinik Pratama, Tempat Praktik Mandiri Dokter, dan Tempat Praktik Mandiri Dokter Gigi dan Instrumen Akreditasi Puskesmas bertujuan untuk menilai keberhasilan pencapaian indikator keselamatan pasien dan digunakan sebagai salah satu upaya peningkatan mutu pelayanan kesehatan.

Pengukuran, pengumpulan dan evaluasi sasaran keselamatan pasien berfungsi sebagai alat untuk menemukan hal-hal yang berpotensi menimbulkan bahaya baik di lingkungan fisik fasilitas pelayanan kesehatan maupun prosedur pelayanan kesehatan yang dilakukan oleh petugas melalui penilaian-penilaian yang berdasarkan pada indikator keselamatan pasien. Hasil pengukuran dan pengumpulan sasaran keselamatan pasien dievaluasi dan digunakan sebagai bahan untuk menciptaan pelayanan kesehatan yang aman dan bermutu baik dari lingkungan fisik maupun prosedur pelayanan kesehatan oleh petugas. Hal tersebut dapat disebut juga proses manajemen upaya keselamatan pasien.

Pengukuran sasaran keselamatan pasien di Puskesmas X Kota Serang dilakukan di setiap unit kerja dan poli. Kemudian hasil pengukuran dikumpulkan dan dievaluasi dalam rapat manajemen risiko guna menghasilkan rekomendasi dan rencana tindak lanjut. Hasil evaluasi upaya keselamatan pasien akan digunakan sebagai bahan perbaikan dan peningkatan mutu pelayanan di Puskesmas $\mathrm{X}$ Kota Serang yang diintegrasikan dengan seluruh aspek dalam pelayanan kesehatan yang disediakan oleh Puskesmas X Kota Serang. Evaluasi hasil perbaikan upaya keselamatan pasien bertujuan untuk melihat apakah setelah perbaikan masalah keselamatan pasien tersebut sudah teratasi atau belum. Apabila masih belum teratasi, maka tim keselamatan pasien harus merekomendasikan tindak lanjut alternatif lain guna mengatasi masalah tersebut.

Terdapat 6 indikator keselamatan pasien yang digunakan sebagai bahan evaluasi dalam peningkatan mutu di Puskesmas "X" yaitu tidak terjadinya kesalahan identifikasi pasien dalam pemberian tindakan medis, tidak terjadinya kesalahan pemberian obat kepada pasien, tidak terjadinya kesalahan prosedur tindakan medis dan keperawatan, pengurangan terjadinya risiko infeksi di Puskesmas, tidak terjadinya pasien jatuh, dan kefektifan komunikasi.

Berdasarkan data rekapitulasi monitoring dan evaluasi indikator keselamatan pasien di Puskesmas X tahun 2019, bahwa rerata pencapaian indikator keselamatan pasien pada Trimester I sebesar 98\%, Trimester II sebesar 96,9\%, Trimester III sebesar 96\%, dan Trimester IV sebesar 96,1\%. Hal tersebut menunjukkan bahwa terjadi penurunan kualitas pelayanan ditinjau dari sisi keselamatan pasien. Sehingga perlu adanya tindak lanjut perbaikan terhadap pelaksanaan upaya keselamatan pasien di Puskesmas X supaya dapat meningkatkan kualitas pelayanan.

Jadwal pengukuran, pengumpulan dan evaluasi sasaran keselamatan pasien dilakukan oleh tim keselamatan pasien pada tiap bulan. Namun, terkadang dalam realisasinya tidak sesuai jadwal. 
Berdasarkan wawancara dengan anggota tim keselamatan pasien, hal tersebut dikarenakan keterbatasan waktu dan rendahnya komitmen antar anggota tim keselamatan pasien dalam melaksanakan tugasnya. Berdasarkan penelitian Shobirin (2016), bahwa terdapat hubungan yang signifikan antara komitmen kerja, penerapan manajemen, dan mutu pelayanan kesehatan. Penerapan manajemen akan berjalan dengan baik apabila didukung dengan komitmen kerja antar anggota yang tinggi sehingga dapat meningkatkan mutu pelayanan kesehatan.

Standar keempat adalah evaluasi dan komunikasi hasil perbaikan. Hasil perbaikan upaya keselamatan pasien harus dikomunikasikan dengan baik kepada seluruh pihak yang terlibat agar masalah terkait keselamatan pasien tersebut menjadi pembelajaran penting bagi seluruh pihak baik kepada petugas pemberi pelayanan kesehatan maupun pasien dan diharapkan kekurangan atau keselahan yang terjadi sebelumnya tidak terulang kembali di waktu selanjutnya.

Bentuk dari komunikasi hasil perbaikan upaya keselamatan pasien di Puskesmas X Kota Serang kepada pasien dan pengunjung Puskesmas lainnya adalah melalui papan informasi yang terpasang di ruang tunggu Puskesmas dimana hasil perbaikan dan evaluasinya akan ditempel di papan informasi tersebut dan diperbarui secara periodik. Berdasarkan wawancara dengan ketua tim Manajemen Mutu Puskesmas X Kota Serang, setiap standar upaya keselamatan pasien yang diterapkan di Puskesmas X Kota Serang telah diintergrasikan dengan penerapan upaya kesehatan lainnya di seluruh aspek pelayanan kesehatan yang ada di Puskesmas X Kota Serang dan dikoordinasikan dengan seluruh pihak yang terlibat dan berkepentingan guna mencapai tujuan yang diinginkan dalam peningkatan mutu pelayanan kesehatan di Puskesmas X Kota Serang.

\section{CONCLUSION}

Berdasarkan hasil observasi dan wawancara serta studi literatur terkait mutu pelayanan kesehatan dan keselamatan pasien di Puskesmas X Kota Serang, maka kesimpulan yang diambil adalah Puskesmas harus mampu memberikan pelayanan yang aman dan bermutu agar dapat mencapai tujuan pembangunan yaitu mewujudkan Kecamatan Sehat. Upaya keselamatan pasien merupakan salah satu bentuk upaya peningkatan mutu pelayanan kesehatan yang tercantum Permenkes No. 46 Tahun 2015 tentang Akreditasi Puskesmas, Klinik Pratama, Tempat Praktik Mandiri Dokter, dan Tempat Praktik Mandiri Dokter Gigi. Strategi monitoring yang diterapkan dalam pelaksanaan upaya keselamatan pasien melalui penilaian yang dilakukan oleh pihak ekternal berdasarkan elemen penilaian yang tertuang dalam Instrumen Akreditasi Puskesmas yang dilakukan secara komprehensif dan periodik untuk meningkatkan mutu pelayanan kesehatan. Dan Pelaksanaan upaya keselamatan pasien di Puskesmas X Kota Surabaya belum optimal sebab masih terdapat hambatan dan kekurangan dalam pemenuhan standar upaya keselamatan pasien yang tercantum dalam Instrumen Akreditasi Puskesmas sehingga 2 dari 4 standar upaya keselamatan pasien Puskesmas X Kota Serang perlu dioptimalkan lagi pelaksanaannya agar dapat mencapai tujuan yang diinginkan dalam upaya peningkatanan mutu pelayanan kesehatan. 


\section{ACKNOWLEDGMENTS}

Ucapan terimakasih kepada pihak-pihak terkait terutama pada Dinas Kesehatan Kota Serang, Banten yang telah memberikan izin untuk melaksanakan penelitian di UPT Puskesmas Kota Serang.

\section{REFERENCES}

Azwar, A. (1996) Menuju Pelayanan Kesehatan Yang Lebih Bermutu. Jakarta: Yayasan Penerbitan Ikatan Dokter Indonesia.

Cahyono, J. B. S. B. (2008) Membangun Budaya Keselamatan Pasien dalam Praktik Kedokteran. Yogyakarta: Kanisius.

Firawati, Aumas Pabuty, A. S. P. (2012) 'Pelaksanaan Program Keselamatan Pasien di RSUD Solok', Jurnal kesehatan Masyarakat, 6(2), pp. 73-79. Available at: http://jurnal.fkm.unand.ac.id/index.php/jkma/ article/view/93.

Gunawan, Fajar Yuli Widodo, T. H. (2015) ‘Analisis Rendahnya Laporan Insiden Keselamatan Pasien di Rumah Sakit', Jurnal Kedokteran Brawijaya,28(2), pp. 206-213. Available at: jkb.ub.ac.id/index.php/jkb/article/download/9 62/479.

Humairoh, S. (2017) Platform e-Reporting Kemenkes; Mampukah Mengurangi Hambatan Pelaporan Insiden Keselamatan Pasien Rumah Sakit?, Kompasiana. Available at: https://www.kompasiana.com/syifahumairoh/ 592a801db79373db5833a774/e-reportingkemenkes-mampukah-mengurangi- hambatan-pelaporan-insiden-keselamatan- pasien-rumahsakit (Accessed: 6 Maret 2021).

Institute of Medicine (US) Committee on Quality of Health Care in America. (2001) Crossing the Quality Chasm: A New Health System for the 21st Century. Washington (DC): National Academies Press (US). Available at: https://www.ncbi.nlm.nih.gov/books/NBK222274/.

Kementerian Kesehatan Republik Indonesia (2009) Undang-Undang Republik Indonesia Nomor 36 Tahun 2009 tentang Kesehatan. Indonesia.

Kementerian Kesehatan Republik Indonesia (2014) Peraturan Menteri Kesehatan Republik Indonesia Nomor 75 Tahun 2014 tentang Pusat Kesehatan Masyarakat. Indonesia.

Kementerian Kesehatan Republik Indonesia (2015) Peraturan Menteri Kesehatan Republik Indonesia Nomor 46 Tahun 2015 tentang Akreditasi Puskesmas, Klinik Pratama, Tempat Praktik Mandiri Dokter, dan Tempat Praktik Mandiri Dokter Gigi. Indonesia.

Kementerian Kesehatan Republik Indonesia (2017) Peraturan Menteri Kesehatan Republik Indonesia Nomor 11 Tahun 2017 tentang Keselamatan Pasien. Indonesia. 
Maghfiroh, L. and Rochmah, T. N. (2017) 'Analisis Kesiapan Puskesmas Demangan Kota Madiun Dalam Menghadapi Akreditasi', Jurnal MKMI, 13(4), pp. 329-336. Available at: http://journal.unhas.ac.id/index.php/mkmi/arti cle/view/1665.

Puskesmas 'X' (2017) Rekapitulasi Monitoring dan Evaluasi Indikator Keselamatan Pasien Puskesmas ' $X$ ' tahun 2017. Serang.

Samra, R. et al. (2016) 'How to Monitor Patient Safety in Primary Care? Healthcare Professionals' Views', Journal of the Royal Society of Medicine Open, 7(8), pp. 1-8. doi: $10.1177 / 2054270416648045$.

Shobirin (2016) 'Hubungan Penerapan Manajemen Puskesmas dan Komitmen Kerja Petugas dengan Mutu Pelayanan Pengobatan di Poli Umum Puskesmas Kabupaten Bangkalan', Jurnal Penelitian Administrasi Publik, 2(2), pp. 513-526. Available at: jurnal.untagsby.ac.id/index.php/jpap/article/download/10 06/898.

Stephen P. Robbins, T. A. J. (2008) Perilaku Organisasi. 12th edn. Jakarta: Salemba Empat.

Sumarni (2017) 'Analisis Implementasi Patient Safety Terkait Peningkatan Mutu Pelayanan Kesehatan di Rumah Sakit', Jurnal Ners dan Kebidanan Indonesia, 5(2), pp. 91-99. doi: http://dx.doi.org/10.21927/jnki.2017.5(2).91- 99.

Ulrich, B. and Kear, T. (2014) 'Patient Safety and Patient Safety Culture: Foundations of Excellent Health Care Delivery.', Nephrology Nursing Journal, 41(5), pp. 447-505. Available at: http://www.jointcommission.org/standards_in formation/npsgs.aspx\%0Ahttp://www.ncbi.nl m.nih.gov/pubmed/26295088. 